\title{
Increased Levels of Treg Cells in Bronchoalveolar lavage Fluid And Induced Sputum of Patients with Active Pulmonary SARCOIDOSIS
}

\author{
R. M. Mroz ${ }^{1}$, M. Korniluk ${ }^{1}$, A. Stasiak-Barmuta ${ }^{2}$, M. Ossolinska ${ }^{1}$, E. Chyczewska ${ }^{1}$ \\ ${ }^{1}$ Department of Chest Diseases and Tuberculosis and ${ }^{2}$ Department of Clinical Immunology, Medical University of Bialystok, \\ Bialystok, Poland
}

\begin{abstract}
Objective: It has recently been described that circulatory and BAL regulatory T-cells (Tregs), defined as CD4+CD25highCD127low are increased in patients with active sarcoidosis compared with other interstitial lung diseases.

Material and methods: We studied prospectively $17 \mathrm{pa}-$ tients (10 women, 7 men) of median age 39 years (range 27-65) with active granulomatous lung diseases (GLD) (10 patients with sarcoidosis (BBS), and 7 with hypersensitivity pneumonitis (HP), and 9 healthy controls. Bronchoalveolar lavage fluid (BAL) and induced sputum Treg counts, CD4+, CD8+, CD25+ cells were quantified by flow cytometry. Disease activity was measured by ACE serum level. Pulmonary function tests were performed using an Elite DL Medgraphics body box.

Results: We found Treg cells count significantly elevated in induced sputum from active GLD (38.3\% vs. $7.1 \%$ and $5.3 \%$ in BBS, HP, and control, respectively). A significantly higher percentage of Treg cells characterized BAL cells from HP patients (2.27\%; 9.5\%; $2.1 \%$, in BBS, HP and control, respectively). There was a strong correlation with ACE serum level and Treg cell count in BAL fluid of BBS patients, with no such correlation within HP patient group, nor Treg cell count and pulmonary function tests.

Conclusions: Our data suggest a potential role of CD4+CD25highCD127low induced sputum and BAL lymphocytes from patients with active granulomatous lung diseases and hypersensitivity pneumonitis. An increased number of Treg cells in active GLD may be involved in immune regulation in active granulomatous lung diseases. The results indicate that analysis of these cells could be useful as markers of disease activity in granulomatous lung diseases.
\end{abstract}

Key words: sarcoidosis, hypersensitivity pneumonitis, Treg cells, T cells

\section{INTRODUCTION}

Sarcoidosis is a multisystemic disorder of unknown etiology, characterized by the formation of noncaseating granulomas in affected organs, most commonly the lung $[1,2]$. Non-caseating granulomas also characterize hypersensitivity pneumonitis (HP), an immunologically mediated interstitial lung disease, result- ing from repeated inhalation of various causative antigens, most commonly Thermophilic actinomycetes, in susceptible individuals [3, 4]. Abnormalities in the bronchoalveolar lavage (BAL) fluid and induced sputum cell counts are almost always seen in patients with both disorders, with predominant $\mathrm{T}$ CD4+ and $\mathrm{T}$ CD8+ cells in sarcoidosis and HP, respectively [5, 6]. It has recently been described that circulatory and BAL regulatory T-cells (Tregs), defined as CD4+CD25highCD127low are increased in patients with active sarcoidosis compared with other interstitial lung diseases [7]. These cells are considered to play a major role in the control of immune responses against self and exogenous antigens [8, 9]. Therefore, the aim of the study was to evaluate a potential role of CD4+CD25highCD127low Treg cells in sarcoidosis (BBS) and HP.

\section{MATERIAL AND METHOds}

Each subject Studied gave written informed consent. Study protocol was approved by the University Ethics Committee. Seventeen non-smoking patients (10 women, 7 men) of median age 39 years (range 27-65) with granulomatous lung diseases, 10 patients with BBS ( 7 women and 33 men) and 7 patients with HP (3 women and 4 men) and 9 healthy subject ( 5 women and 4 men, median age 48 years (39-63) as a control, were studied. Diagnosis was based on medical history, clinical symptoms (cough and/or exertional dyspnea), standard chest radiography, CT scanning, lung function tests, and laboratory test results (serum angiotensin-converting enzyme - ACE) following the American Thoracic Society/European Respiratory Society/World Association of Sarcoidosis and Granulomatous Disorders statement [1]. According to chest radiography staging of sarcoidosis, all 10 patients had stage II disease, confirmed with high resolution computed tomography (HRCT) findings which were lymphadenopathy and parenchymal opacities. The diagnosis was confirmed by lung transbronchial biopsy specimen. All HP patients fulfilled the following diagnostic criteria: 1) a history of exposure to organic antigens; 2) clinical signs and symptoms consistent with HP; 3) radiographical features and/or functional abnormalities characteristic of interstitial lung disease; 4) evidence of serum precipitins against one or more organic antigens; and 5) increased lymphocytes in the BAL 
fluid. All 7 patients presented with the subacute form of the disease. Positive serum precipitins against Termoactinomyces vulgaris was confirmed in all HP cases. All patients showed widespread and dominant ground-glass densities in HRCT, with only minor reticulation and no honeycombing. None of the patients received oral or inhaled glucocorticoids or antibiotics during the 6 months preceding the study. They were lifetime non-smokers and did not experience any acute respiratory illnesses during the 6 weeks prior to the study.

Lung function and DLCO tests were performed with a body box (Elite DL, Medgraphics, USA). The measurement was performed using standard protocols according to American Thoracic Society/European Respiratory Society guidelines [10]. Bronchoscopy and BAL processing was performed as part of routine clinical management, according to the recommended guidelines and previous reports [11]. Subjects underwent bronchoscopy by flexible fiberoptic bronchoscope (Pentax FB 18 V; Pentax Corporation, Tokyo, Japan). Subjects received atropine (0.5 mg, i.m.), and midazolam (5 mg, i.m.). Then, local anaesthesia was performed by inhalation of an aerosol solution of 22 $\mathrm{ml}$ of $2 \%$ lidocaine $15 \mathrm{~min}$ before bronchoscopy. BAL was carried out as previously described [12]. The bronchoscope was inserted and wedged in the right middle lobe, and three $50 \mathrm{ml}$ aliquots of sterile saline solution, warmed at $37^{\circ} \mathrm{C}$, were instilled into the subsegmental bronchus. Fluid was gently aspirated immediately after each aliquot was introduced, and collected in a sterile container. The first $50 \mathrm{ml}$ aliquot of recovered fluid was labeled as BW (data not shown). Another aliquot of recovered fluid was labeled BAL. The BAL fluid samples were analyzed for total and differential cell counts, flow cytometry to measure CD3+, CD4+, and CD8+ and Treg cell counts. During the bronchoscopy, oxygen saturation and ECG tracings were continuously monitored. One aliquot was reserved for total cell number using Nageotte's chamber, and results were expressed as cells $\mathrm{x} 105 / \mathrm{ml}$. The remaining fluid was immediately centrifuged at $800 \mathrm{rpm}$ for $10 \mathrm{~min}$ at $4^{\circ} \mathrm{C}$. The cell pellet was washed twice with phosphate-buffered saline solution (without $\mathrm{Ca} 2+$ and $\mathrm{Mg} 2+)$. Cytocentrifugates were stained by the May-Grünwald-Giemsa method.

The differential cell count of macrophages, neutrophils, lymphocytes, eosinophils, and epithelial cells was made under a light microscope (magnification $\mathrm{x}$ 1000 ) by counting at least 400 cells. Two observers blinded to the patients' characteristics counted 400 cells to determine the differential cell count. A further $2 \mathrm{ml}$ of lavage fluid was resuspended in HBSS and layered onto a density gradient medium (Histopague-1077, Sigma Diagnostics, Poole, UK) and cytocentrifuged at 600 $\mathrm{g}$ for $10 \mathrm{~min}$. The cell pellet was then resuspended in HBSS and incubated with $10 \%$ bovine serum albumin (Sigma Diagnostics, Poole, UK) for $20 \mathrm{~min}$.

Flow cytometric analysis of BAL and induced sputum. Flow cytometry was performed using an Epics XL flow cytometer (Coulter Electronics, Hialeah, USA) that detects lymphocytes by fluorescence. To enhance the number of lymphocytes for analysis, an acquisition gate was set using the lower third of the side scatter field. The analysis gate was broad in order to exclude non-lymphocytic cells. Results were expressed as the percentage of the cells detected by fluorescence. Pairs of monoclonal antibodies to $\mathrm{CD} 3+$, CD4+, CD8+, CD25+, and CD127+ cells (Sigma Diagnostics, Poole, UK) were then added to the suspension and incubated for $30 \mathrm{~min}$ after which flow cytometry was performed.

All analyses were performed using a statistical software package (Statistica for Windows, StatSoft, Tulsa, $\mathrm{UK})$. The results are expressed as means $\pm \mathrm{SD}$ or median (range), unless otherwise indicated. The ShapiroWilk W test for normality was applied to assess normality. The Mann Whitney U test for non-normally distributed variables and Spearman's correlation were used. $\mathrm{P}<0.05$ was considered to be statistically significant.

\section{RESULTS}

Table 1. Demographics, laboratory and lung function tests comparison between the sarcoidosis and control groups.

\begin{tabular}{|c|c|c|c|c|}
\hline & $\begin{array}{l}\text { Sarcoidosis } \\
n=10\end{array}$ & $\begin{array}{l}\mathbf{H P} \\
\mathrm{n}=7\end{array}$ & $\begin{array}{l}\text { Control } \\
\mathrm{n}=9\end{array}$ & $\mathbf{P}$ \\
\hline Age (yr) & $39(27-65)$ & $42(28-61)$ & 0.48 & \\
\hline $\mathrm{ACE}(\mathrm{U} / \mathrm{l})$ & 61 & 76 & 23 & 0.0004 \\
\hline Macrophages BAL/induced sputum (\%) & $63 / 36.9$ & $34 / 23.7$ & $81 / 45$ & $0.0032 / 0.045$ \\
\hline Lymphocytes BAL/induced sputum (\%) & $34 / 5.2$ & $57 / 8.1$ & $14 / 2.4$ & $0.0002 / 0.0002$ \\
\hline Neutrophils BAL/induced sputum (\%) & $1 / 54$ & $1 / 63.7$ & $1 / 51$ & $0.00005 / 0.67$ \\
\hline Eosynophiles BAL/induced sputum (\%) & $1 / 0$ & $1 / 1$ & $1 / 1$ & NS/NS \\
\hline CD4 BAL/induced sputum (\%) & $59 / 32$ & $20 / 27$ & $36 / 24$ & $0.00001 / 0.032$ \\
\hline CD8 BAL/induced sputum (\%) & $20 / 14$ & $5 / 21$ & $17 / 11$ & $0.350 / 0.46$ \\
\hline $\mathrm{CD} 4 / \mathrm{CD} 8$ ratio BAL/induced sputum & $2.8 / 5.0$ & $0.04 / 1.2$ & $1.9 / 1.3$ & $0.0002 / 0.0045$ \\
\hline CD4/25 high/127 low BAL/induced sputum & $2.3 / 38.3$ & $9.5 / 7.1$ & $2.1 / 5.3$ & $0.7 ; 0.006 / 0.0034 ; 0.0043$ \\
\hline Ca plasma $\mathrm{mmol} / \mathrm{l}$ & 2.4 & 2.2 & 2.3 & 0.7 \\
\hline $\mathrm{Ca} 24$-h urine $\mathrm{mmol} / \mathrm{l}$ & 6.1 & 6.4 & 5.7 & 0.21 \\
\hline
\end{tabular}

Values are median (range); NS-non specific. 

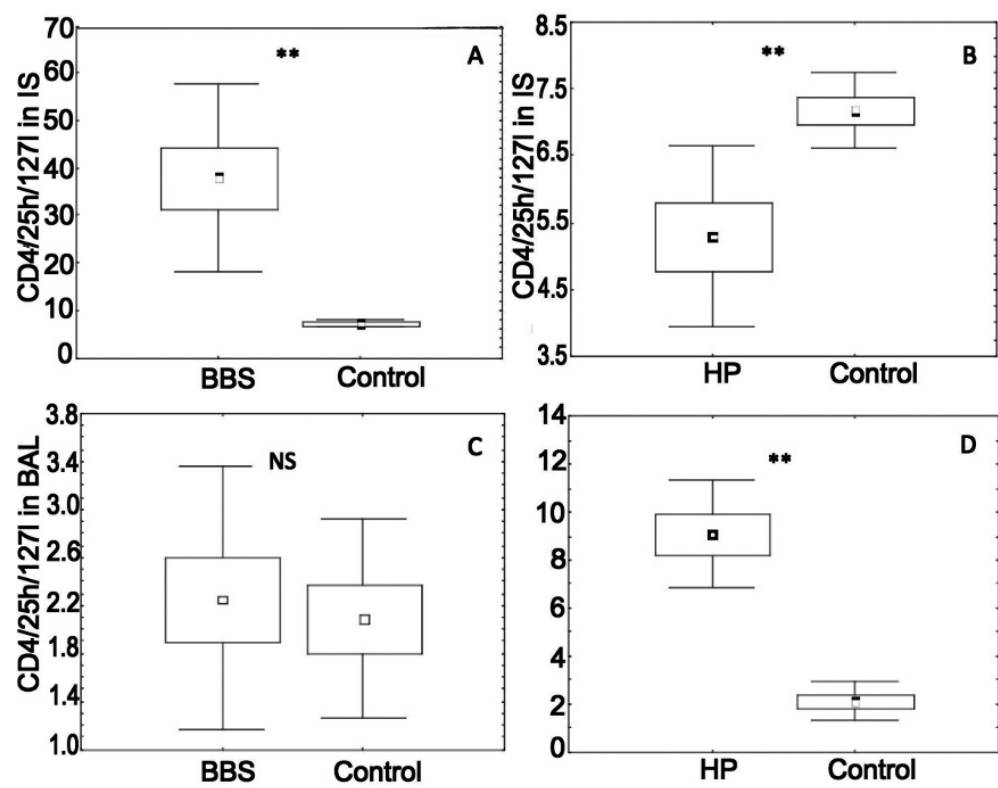

Fig. 1. CD4+high/127low Treg in induced sputum and BAL of patients with sarcoidosis (BBS) and hypersensitivity pneumonitis (HP). Panel A induced sputum in BBS, Panel B - induced sputum in HP, Panel C - BAL in BBS, and Panel D BAL in HP patients.
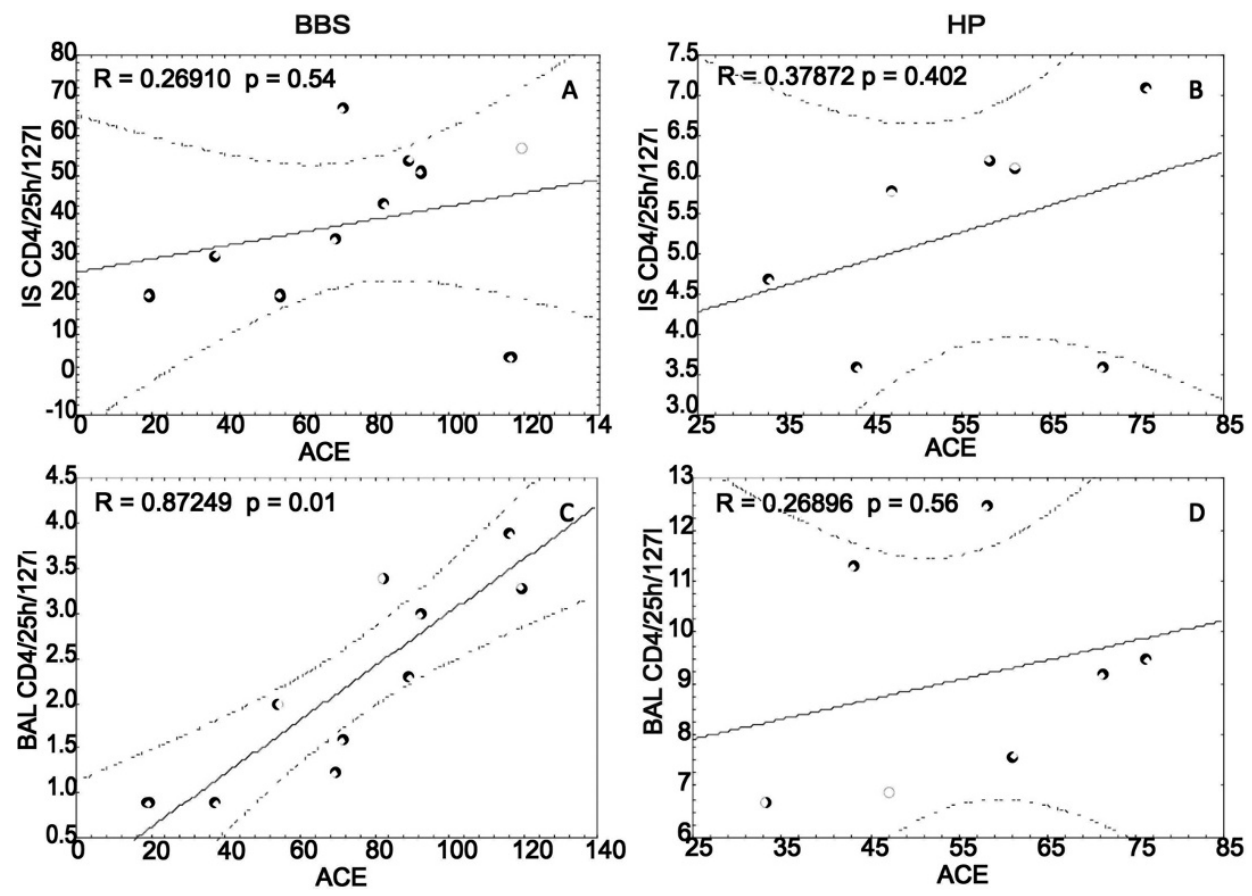

Fig. 2. ACE/Treg cell correlations in sarcoidosis (BBS) and hypersensitivity pneumonitis (HP).patients. Panel A - induced sputum in BBS, Panel B - induced sputum in HP, Panel $\mathrm{C}-\mathrm{BAL}$ in BBS, and Panel D - BAL in HP patients.

Demographic, clinical, and BAL/induced sputum cellular characteristics of the subjects studied are displayed in Table 1. The BBS and HP groups were characterized by a significantly higher median range of plasma ACE concentration $(61,76$, vs. $23 \mathrm{U} / 1$ in BBS, $\mathrm{HP}$ vs. control, respectively, $\mathrm{P}<0.0004)$, with no difference in regard to $\mathrm{Ca} 2+$ serum concentration and urine 24-h Ca2+ excretion of patient group in comparison with the control group (Table 1). There were no differences regarding lung function tests or $\mathrm{SaO} 2$ (data not shown).

We found a significantly higher lymphocyte percentage in BAL and induced sputum $(34,57$, vs. $14 \%$, $\mathrm{P}<0.0002$, and $5.2,8.1$, vs. $2.4, \mathrm{P}=0.0002$, in $\mathrm{BBS}, \mathrm{HP}$ vs. control, respectively). The percentage of macrophages was significantly lowered in the study group. The BBS patients had a significantly higher percentage of CD4+ cells in BAL and induced sputum (59 vs. 36, and 32 vs. 24, respectively) and $\mathrm{CD} 4 / \mathrm{CD} 8$ ratio in both fluids (2.8 vs. $1.9, \mathrm{P}=0.0002$, and 5.0 vs. $1.3, \mathrm{P}=$ $0.0045)$ (Table 1). HP patients were characterized by higher induced sputum CD8+ cells (21 vs. $11, \mathrm{P}=$ 0.46 ). All subjects tolerated induced sputum and bronchoscopy procedure well, without any adverse events.

The CD4/25 high/127 low induced sputum percentage was significantly higher in sarcoidosis and HP patients in comparison with healthy subjects (38.3, 7.1, and $5.3 \%$, in sarcoidosis, HP and control, respectively, $\mathrm{P}=0.0034$, and $\mathrm{P}=0.0043$ ) (Table 1 , Fig $1 \mathrm{~A}$ and $1 \mathrm{~B}) . \mathrm{A}$ higher percentage of BAL Treg cells characterized HP patients, with insignificant elevation of these cells in BBS group $(2.3,9.5$ and $2.1 \%$, in BBS, HP and control, respectively, $\mathrm{P}=0.7$ and $\mathrm{P}=0.006$ ) (Table 1 , Fig. $1 \mathrm{C}$ and $1 \mathrm{D})$.

Correlations within the BBS group showed strong positive correlation between BAL Treg cells and 
serum ACE level ( $\mathrm{r}=0.873, \mathrm{P}=0.01$ ) (Fig. 2C) with no such correlations regarding induced sputum BBS Treg cells (Fig. 2A). There was no significant correlation between the serum ACE level and Treg cells in regard to the HP patient group (Fig. 2B and 2D). There was no correlation in regard to Treg cell count and pulmonary function tests (data not shown).

\section{Discussion}

The present study demonstrates that the percentage of lymphocytes, TCD4+, CD4/CD 8 ratio of $\mathrm{BAL}$ and induced sputum samples from newly diagnosed, untreated patients with active pulmonary sarcoidosis were significantly higher in comparison with the control group. Also, we demonstrated a significantly higher percentage of lymphocytes and TCD8+, with lower CD4/CD8 ratio of BAL and induced sputum samples from newly diagnosed untreated patients with active $\mathrm{HP}$ patient in comparison with the control group. The number of lymphocytes obtained from BAL and induced sputum in our group of patients with newly diagnosed sarcoidosis and HP is similar to that reported previously by us and others $[5,6,13,14]$. The assessment of lymphocyte counts and CD4/CD 8 ratio in BAL samples is still recommended in clinical evaluation of patients with active granulomatous disorders such as sarcoidosis and HP $[11,12,15,16]$. CD4/CD8 ratio in BAL fluid from HP patients may vary according to the clinical course of the disease, the type of the inhalation antigen, the extent of the exposure to the sensitizing antigen, the immune susceptibility of the patients, smoking habits, etc $[5,13,16,17]$. In the present study, the only sensitizing antigen was Thermoactinomyces vulgaris.

Assessing Treg cells, we found their count significantly elevated in induced sputum from active granulomatous lung disease with the highest number obtained from the BBS patient group. There was a strong correlation with the ACE serum level and Treg cell count in BAL fluid of BBS patients, with no such correlation in the HP patient group or between Treg cell count and pulmonary function tests (data not shown). Miyara et al [7] found CD4+CD25(bright)FoxP3+ cells accumulating at the periphery of sarcoid granulomas, in bronchoalveolar lavage fluid, and in peripheral blood of patients with active disease. These cells exhibited powerful antiproliferative activity, yet they did not completely inhibit TNF-alpha production. The authors concluded that sarcoidosis may be associated with a global T reg cell subset amplification whose activity would be insufficient to control local inflammation. At the same time, peripheral Treg cells exerting powerful antiproliferative activity may account for the state of anergy. Moreover, Taflin et al [18] found that CD4(+)CD45RA(-)FoxP3(bright) Tregs proliferate and accumulate within granulomas. Circulating and tissue Treg numbers did not correlate with the dissemination of the disease or with the extent of granulomatous inflammation. Treg depletion accelerated in vitro granuloma growth in mononuclear cell cultures of healthy controls, but not in those from patients with active sarcoidosis. Healthy Tregs suppressed the initial steps of granuloma formation, with no positive influ- ence on sarcoidosis lesions, thus, arguing for a more preventive than curative effect of Tregs on inflammatory processes. On the other hand, Idali et al [19] found that mRNA expression of FoxP3, CCR2, and IL-10 decreased significantly in BALF CD4+ T cells of patients with active sarcoidosis. Moreover, flow cytometric analysis of CD4+ T cells also demonstrated a decreased frequency of FoxP3+ cells in the BALF and blood of sarcoidosis patients and a reduced intensity of FoxP3 expression in BALF FoxP3+ cells of patients. BALF CD4+AV2S3+ T cells expressed significantly lower levels of FoxP3 and CCR2 mRNA vs. BALF CD4+AV2S3- T cells. The authors concluded that there is a reduced expression of regulatory $\mathrm{T}$ cell associated genes in BALF CD4+ T cells in sarcoidosis [19]. Our data suggest a potential role of CD4+CD25highCD127low induced sputum and BAL lymphocytes from patients with active BBS and HP. An increased number of Treg cells in active granulomatous lung disease may be involved in immune regulation in active granulomatous lung diseases. The results indicate that analysis of these cells could be useful as markers of disease activity in granulomatous lung disease. Further large-scale studies are needed to define the precise role of Treg cells in the immunopathogenesis of granulomatous lung disease.

Conflicts of interest: The authors had no conflicts of interest to declare in relation to this article.

\section{REFERENCES}

[1] Hunninghake GW, Costabel U, Ando M, Baughman R, Cordier JF, du Bois R, Eklund A, Kitaichi M, Lynch J, Rizzato G, Rose C, Selroos O, Semenzato G, Sharma OP. ATS/ERS/WASOG statement on sarcoidosis. American Thoracic Society/European Respiratory Society/World Association of Sarcoidosis and other Granulomatous Disorders. Sarcoidosis Vasc Diffuse Lung Dis 1999; 16(2): 149-73.

[2] Mitchell DN, Scadding JG, Heard BE, Hinson KF. Sarcoidosis: histopathological definition and clinical diagnosis. J Clin Pathol 1977; 30(5): 395-408.

[3] Fink, J. N. 1992. Hypersensitivity pneumonitis. Clin Chest Med 13: 303-9.

[4] Sharma OP, Fujimura N. Hypersensitivity pneumonitis: a noninfectious granulomatosis. Semin Respir Infect 1995; 10: 96-106.

[5] Mróz RM, Chyczewska E, Korniluk M, Stasiak-Barmuta A, Ossoli_ska M. Comparison of cellular composition of induced sputum, bronchial washings and bronchoalveolar lavage fluid in sarcoidosis, hypersensitivity pneumonitis and COPD. Pneumonol Alergol Pol 2002; 70(9-10): 46877.

[6] Mroz RM, Korniluk M, Stasiak-Barmuta A, Chyczewska E. Comparison of induced sputum and bronchoalveolar lavage fluid cell profile during the treatment of pulmonary sarcoidosis. J Physiol Pharmacol 2007; 58 Suppl 5(2): 445-52.

[7] Miyara M, Amoura Z, Parizot C, Badoual C, Dorgham K, Trad S, Kambouchner M, Valeyre D, Chapelon-Abric C, Debré P, Piette JC, Gorochov G. The immune paradox of sarcoidosis and regulatory $\mathrm{T}$ cells. J Exp Med 2006; 203(2): 359-70

[8] Sakaguchi S. Naturally arising CD4+ regulatory t cells for immunologic self-tolerance and negative control of immune responses. Annu Rev Immunol 2004; 22: 531-62. 
[9] Sakaguchi S, Yamaguchi T, Nomura T, Ono M. Regulatory T cells and immune tolerance. Cell 2008; 133: 775-87.

[10] Miller MR, Crapo R, Hankinson J, Brusasco V, Burgos F, Casaburi R, Coates A, Enright P, van der Grinten CP, Gustafsson P, Jensen R, Johnson DC, MacIntyre N, McKay R, Navajas D, Pedersen OF, Pellegrino R, Viegi G, Wanger J; ATS/ERS Task Force. General considerations for lung function testing. Eur Respir J 2005; 26(1): 15361.

[11] Technical recommendations and guidelines for bronchoalveolar lavage (BAL). Report of the European Society of Pneumology Task Group. Eur Respir J 1989; 2(6): 561-85.

[12] Haslam PL, Baughman RP. Report of ERS Task Force: guidelines for measurement of a cellular components and standardization of BAL. Eur Respir J 1999; 14(2): 245-8.

[13] Semenzato G, Chilosi M, Ossi E, Trentin L, Pizzolo G, Cipriani A, Agostini C, Zambello R, Marcer G, Gasparotto G. Bronchoalveolar lavage and lung histology. Comparative analysis of inflammatory and immunocompetent cells in patients with sarcoidosis and hypersensitivity pneumonitis. Am Rev Respir Dis 1985; 132(2): 400-4.

[14] Ward K, O'Connor C, Odlum C, FitzGerald MX. Prognostic value of bronchoalveolar lavage in sarcoidosis: the critical influence of disease presentation. Thorax 1989; 44(1): 6-12.

[15] Mroz RM, Korniluk M, Stasiak-Barmuta A, Chyczewska E. Increased levels of interleukin-12 and interleukin 18 in bronchoalveolar lavage fluid of patients with pulmonary sarcoidosis. J Physiol Pharmacol 2008; 59 Suppl 6: 50713.
[16] Mroz RM, Korniluk M, Stasiak-Barmuta A, Chyczewska E. Upregulation of Th1 cytokine profile (IL-12, IL-18) in bronchoalveolar lavage fluid of patients with hypersensitivity pneumonitis. J Physiol Pharmacol 2008; 59 Suppl 6: 499-505.

[17] Murayama J, Yoshizawa Y, Ohtsuka M, Hasegawa S. Lung fibrosis in hypersensitivity pneumonitis. Association with CD4+ but not CD8+ cell dominant alveolitis and insidious onset. Chest 1993; 104:38-43.

[18] Taflin C, Miyara M, Nochy D, Valeyre D, Naccache JM, Altare F, Salek-Peyron P, Badoual C, Bruneval P, Haroche J, Mathian A, Amoura Z, Hill G, Gorochov G. FoxP3+ regulatory $T$ cells suppress early stages of granuloma formation but have little impact on sarcoidosis lesions. Am J Pathol 2009; 174(2): 497-508.

[19] Idali F, Wahlström J, Müller-Suur C, Eklund A, Grunewald J. Clin Exp Immunol 2008; 152(1): 127-37.

Author's address:

Robert M. Mroz

Department of Lung Diseases and Tuberculosis

Medical University of Bialystok

Zurawia 14 St.

15-540 Bialystok, Poland

Phone: +48 857409530

Fax: $\quad+48856545419$

E-mail: Robmroz@wp.pl 